\section{Free CPD on enamel erosion}

Regenerate has launched a new learning portal focussed on enamel erosion which provides free CPD for dental professionals.

A core feature of the Learning Resources portal is five CPD modules, each of an hour in length, which cover different aspects of erosive enamel wear:

- New Perspectives on Enamel Erosion: From Diagnosis to Prevention

- Enamel Erosion: Tooth Wear

- Enamel Erosion

- Enamel Erosion: Diagnosis

- Enamel Erosion: Unilever Lunch and Learn.

Each of the five free e-learning modules confers an hour of verifiable $\mathrm{CPD}$, and is accredited by Healthcare Learning. A downloadable certificate is provided on completion of each of the modules.

Unilever sponsored an expert symposium at IADR 2018 in London which featured some of the world's leading experts in the field of enamel erosion including Professor Bartlett, Professor Buzalaf, Professor Unwin \& Dr Joiner who discussed 'A Clinical Perspective on the Erosion Challenge: Diagnosis to Prevention'. It is possible to view a film of the expert symposium on the CPD portal - which is the next best thing to actually attending the event.

In addition, the portal features a number of clinical papers about the technology behind the REGENERATE Enamel Science range which is the first oral care regime with NR-5 technology able to regenerate enamel mineral. A summary document containing all the studies can also be downloaded.

\section{Full arch immediate loading course}

In association with Quest Dental Implant Education, Trycare Ltd are hosting a two-day Full Arch Immediate Loading Surgical and Restorative Course with Live Surgery in Edinburgh on 1 and 2 November 2019.

With only limited places available they anticipate demand will be high so early booking is recommended.

The course is aimed at implantologists who are already placing implants to restore single and multiple units and want to go to the next level for full arch replacement. It will be led by Dr Girish Bharadwaj, a Specialist Oral Surgeon with a wide range of experience in oral surgery, sedation and implantology. The course has been designed so that at the end of it delegates will have sufficient knowledge to plan and place implants and deliver an immediate fixed prosthesis with immediate loading. It will provide 14 hours of enhanced CPD with development outcomes C and D.

The Delegate Course Fee is $£ 995.00$ including vat. This fee includes two days' tuition, lunch, refreshments and the delegates' dinner on Friday night.

For further details contact Denise Law at Trycare via denise. law@trycare.co.uk or 01274885540 . Alternatively visit www. trycare.co.uk/full-arch-course.

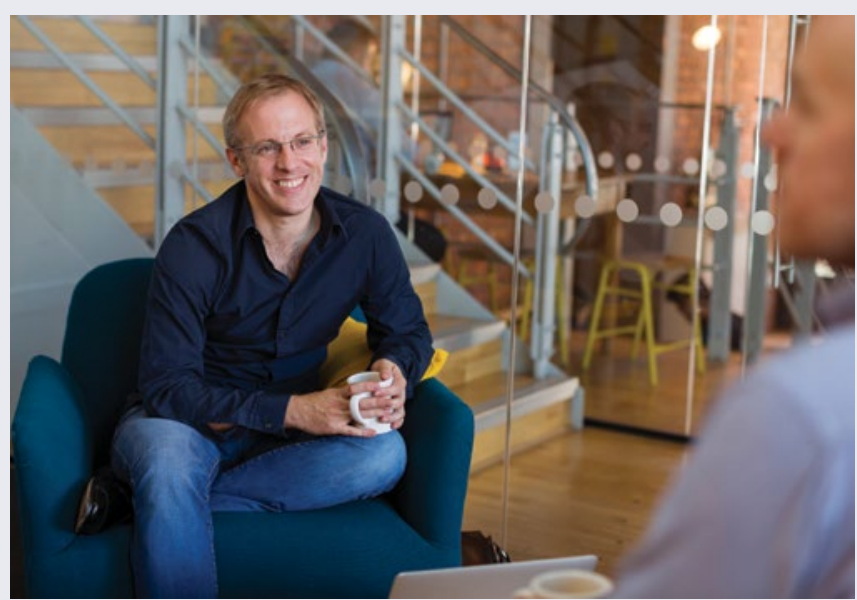

Videos demonstrating the mode of action of the REGENERATE Enamel Science Advanced Toothpaste and Advanced Enamel Serum can also be viewed on the portal.

In addition, a downloadable guide to diagnosing enamel erosion in clinic as well as a range of patient resources including three patient brochures, clinic posters and leaflets about enamel erosion are available. Dental professionals can also link to the Erosive Tooth Wear Foundation and access a range of videos featuring Professor David Bartlett explaining enamel erosion.

The next free verifiable CPD session is a webinar lecture delivered by Dr Ben Atkins (pictured), President Elect of the Oral Health Foundation in September 2019, on the Healthcare Learning platform. A link to the webinar will be available on the portal in due course.

The portal is free for all dental professionals and can be accessed here: https://www.regeneratenr5.co.uk/pages/learning-resources.

\section{Say goodbye to grey gingiva}

The metal components of traditional dental implants can become visible through the gingiva. Why take this risk with your patients when TBR offers a superior alternative?

Say goodbye to grey gingiva with the revolutionary $\mathrm{Z} 1$ implant. It combines a titanium body with an innovative zirconia collar that acts as an antibacterial shield, protecting the crestal bone and the gingiva from iatrogenic inflammation. Moreover, it encourages the soft tissue to heal around the implant in a manner that closely resembles natural gingival growth.

Call today to find out how you could ensure a highly aesthetic outcome with the $\mathrm{Z} 1$ - now available with a zirconia

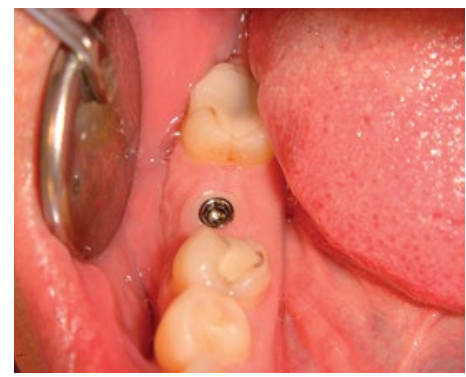
collar height of $1.5 \mathrm{~mm}$ or $2.5 \mathrm{~mm}$.

For more information on the $\mathrm{Z} 1$ implant, visit tbr.dental, email support@denkauk.com or call 08007076212. 